\title{
Performance Characteristics of Silane Silica Modified Asphalt
}

\author{
Xuedong Guo, Mingzhi Sun, Wenting Dai, and Shuang Chen
}

School of Transportation, Jilin University, Changchun 130022, China

Correspondence should be addressed to Wenting Dai; daiwt@jlu.edu.cn

Received 4 December 2015; Accepted 10 February 2016

Academic Editor: Ying Li

Copyright (c) 2016 Xuedong Guo et al. This is an open access article distributed under the Creative Commons Attribution License, which permits unrestricted use, distribution, and reproduction in any medium, provided the original work is properly cited.

\begin{abstract}
At present there are many kinds of fillers and modifier used for modified asphalt, but the effect of modifier differs in thousands of ways; most of them can increase the high temperature performance of asphalt, but the modified effect of low-temperature crack resistance, water stability, and antifatigue performance is different. Aiming at the subsistent problems, this paper innovatively puts forward the idea of taking the silane silica (nanosilica modified with silane coupling agent) as filler to develop one kind of modified asphalt concrete which has excellent comprehensive performance based on the idea of enhance the whole performance of asphalt concrete and interface consolidation strength between aggregate and asphalt at the same time. The best mixing amount of silane silica and the production process of modified asphalt were conducted by contrasting the test date as penetration, viscosity, and softening point; the aging of asphalt and modified asphalt was analyzed by TG test, the superiority of silane silica modified asphalt is more clearly understandable by chemical analysis results. Meanwhile it is proved that silane silica has positive effect to improve the mixture of high and low temperature performance, water stability, and aging resistance through a series of road performance tests.
\end{abstract}

\section{Introduction}

Asphalt has complicated chemical composition which exhibits both viscous and elastic properties that heavily depend on both time and temperature. Researchers and engineers have been trying to use various kinds of modifiers to modify and improve the asphalt materials' performance; up to now the main kinds of modifiers had polymers (such as SBS, rubber, and resin [1-3]), antistripping agent (such as lime ash, alkaline saponin, and coupling agent [4]), fiber (such as steel fiber, wood fiber, basalt fiber, polyester fiber, glass fiber, and carbon fiber [5-7]), and filler (such as carbon black, sulfur, diatomite, and silica [8-14]). The effects of various modifiers are different; in general a certain kind of modifier has only one or a few positive effects on high and low temperature performance, aging performance, or water stability. Therefore, it is of great significance to develop a modified asphalt of comprehensive performance, and the research work has a long way to go.

In recent years, nanotechnology has been widely used in many fields as a new technology with broad prospects and rich creativity. Many researchers have used nanomaterials for cement, but the nanomaterial modified asphalt is relatively late compared to modified concrete. Because of the very small size and huge surface area, nanomaterials can achieve the same effect of the ordinary material only by adding relatively little amount. The research on nanoclay by You et al. [8] and Jahromi and Khodaii [9] showed that it can significantly improve asphalt softening point, reduce needle penetration and ductility, improve the antiaging performance by adding little dosage of nanoclay, and improve the rheological properties of asphalt by enhancing the toughness and elasticity of asphalt at the same time. The research by Yao et al. [13] showed that the $2 \%-4 \%$ nanosilica can reduce the rutting depth to nearly half. However, it has not been able to get a good solution for the problem that inorganic nanomaterials have poor dispersal ability to mix together with the organic asphalt and inorganic materials are easy to agglomerate. This paper is proposed to solve the above problems by using one kind of nanosilica which is modified with silane coupling agent (hereinafter called silane silica).

The situation that silane silica used in rubber, paint, plastic, and other industry applications is getting better and better [15-20]. As new materials, more and more researchers 
pay attention to it, but it is almost in a blank stage that the silane silica is used as modifier to improve the adhesion between asphalt and aggregate and the road performance of asphalt mixture. As a superiority modifier due to its potentially beneficial properties (e.g., strong adsorption, huge surface area, good stability, and excellent dispersal ability), silane silica has not really been recognized in the using process of the asphalt pavement. The objective of this study is to evaluate the modified effect and process with silane silica in order to improve the overall road performance of asphalt mixture and enhance the adhesion between asphalt and aggregate.

\section{Raw Material Property and Mechanism of Action}

2.1. Mechanism Analysis of Modified Material. The special properties of nanoscale modified materials due to the mesoscopic size are the hot spots in the research of composite materials. Due to the large surface of inorganic nanomaterials and the poor compatibility between inorganic and organic phase, ordinary nanosilica particles in asphalt will cluster easily, and it is hard to achieve uniform and stable dispersion through high speed stirring. Grafting modification of nanosilica by using silane coupling agent can not only realise inorganic material surface modification but also reduce the surface energy of inorganic materials and also make distribution of inorganic materials in organic matrix materials more uniform.

In addition, silane contains two different chemical functional groups by chemical bonding theory analysis, and one end reacts with hydroxyl groups of inorganic materials (such as silica particles, aggregate) to form a covalent bond; the other end can form stationary phase with organic functional groups of asphalt molecular through chemical reaction. So it can be considered that the silane has a bridging effect on the organic-inorganic system. From the standpoint of the mechanism of silane, particles of nanosilica modified by silane can better dissolve and disperse into asphalt, and the strength and toughness of asphalt binder can improve greatly. Besides, the material disposed by silane can form an organic coupling agent film on the surface and aggregate change from hydrophily into lipophilicity which provides the basis for the consolidation enhancement of the interface between asphalt and aggregate. Therefore, the mechanical strength and the impact toughness of the composite modified asphalt are much better than the matrix asphalt, and it will have good high temperature performance, antiaging, antifatigue, and other properties.

\subsection{Raw Material}

2.2.1. Silane Silica. The hydrophobic silane silica which is selected to modify asphalt is silica which reacts with silane coupling agent. The contact angle is reaching $70^{\circ}$ to $150^{\circ}$ of hydrophilic silica after surface modification and the surface has grafted polysiloxane which successfully changes the hydrophilic silica into excellent hydrophobic silane silica. The main technical indicators of silane silica are shown in Table 1.
TABLE 1: Physical properties of silane silica.

\begin{tabular}{lc}
\hline Project & Index \\
\hline Model & Silane silica \\
\hline Appearance & White powder \\
\hline Whiteness $\%$ & $\geq 93$ \\
\hline Silica content $($ dry goods $) / \%$ & $\geq 98$ \\
\hline PH value & $\geq 7$ \\
\hline BET $($ specific surface area $) / \mathrm{m}^{2} / \mathrm{g}$ & $\geq 220$ \\
\hline DBP $\mathrm{mL} / 100 \mathrm{~g}($ oil absorption capacity) & $\geq 270$ \\
\hline Particle size $/$ nm & $\leq 100$ \\
\hline Cauterant $($ dry goods $)\left(1000^{\circ} \mathrm{C}, 2 \mathrm{~h}\right) / \%$ & $\leq 7.0$ \\
\hline Heating reduction $\left(105^{\circ} \mathrm{C}, 2 \mathrm{~h}\right) / \%$ & $\leq 6.0$ \\
\hline
\end{tabular}

2.2.2. Asphalt. Panjin number 90 was chosen to be the base asphalt, and the main technical indexes of asphalt were able to meet the requirements of the standard.

2.2.3. Aggregate. The aggregate is from Jiutai stone material factory which is alkaline aggregate.

\section{Test to Find the Optimum Mixing Amount of Silane Silica}

3.1. Needle Penetration and Penetration Index. 90\# asphalt was used to modify with silane silica; the preparation method of modified asphalt was as follows: First control asphalt was heated to molten state; then silane silica was added into control asphalt at concentrations of $0.5 \%, 1 \%, 1.5 \%, 2 \%, 3 \%$, $4 \%$, and $5 \%$ by weight of the control asphalt and mixed in the high-speed shear machine. During the mixing, the asphalt samples were kept at constant temperature of $160^{\circ} \mathrm{C}$ and blended using a shear rate of $4000 \mathrm{r} / \mathrm{min}$ for an hour. Finally we obtain modified asphalt with different dosage of silane silica added. The optimum mixing amount of silane silica added in asphalt is determined according to the basic index of the asphalt such as penetration, viscosity, and softening point. The penetration and PI value of asphalt under different temperature and content according to the specification of asphalt penetration test are measured in Table 2 .

The test data of Table 2 showed that the denseness of modified asphalt has trend to become bigger with the increasing of silane silica content.

Penetration index with different silane silica content is as shown in Figure 1.

The curve of penetration index showed in Figure 1 has two peaks, respectively, in $0.5 \%$ and $3 \%$. When $3 \%$ silane silica is added, PI index is close to zero; at this point, the sensitivity of the modified asphalt is the least sensitive, which can improve the high temperature stability and low temperature cracking resistance of asphalt mixture, and it can be considered that the $3 \%$ mixing amount is the best. While the mixing amount is more than $3 \%$, PI values show a downward trend. The flow ability of asphalt will become worse rapidly at this time when the trial tested is more than $5 \%$, and it is not conducive to the mixture. 
TABle 2: Penetration and penetration index PI.

\begin{tabular}{lcccc}
\hline Volume & $15^{\circ}$ penetration & $25^{\circ}$ penetration & $30^{\circ}$ penetration & PI \\
\hline $0 \%$ & 31.7 & 81.3 & 133.9 & -0.26 \\
$0.5 \%$ & 25.1 & 82.6 & 124.4 & -1.06 \\
$1.00 \%$ & 29.2 & 65.1 & 113.2 & 0.239 \\
$1.50 \%$ & 27.8 & 73.3 & 128 & -0.61 \\
$2 \%$ & 25.5 & 73.9 & 123.3 & -0.867 \\
$3.0 \%$ & 30 & 74 & 116.7 & 0.116 \\
$4 \%$ & 20.1 & 57.2 & 90 & -0.566 \\
$5 \%$ & 19 & 64.3 & 87.1 & -0.816
\end{tabular}

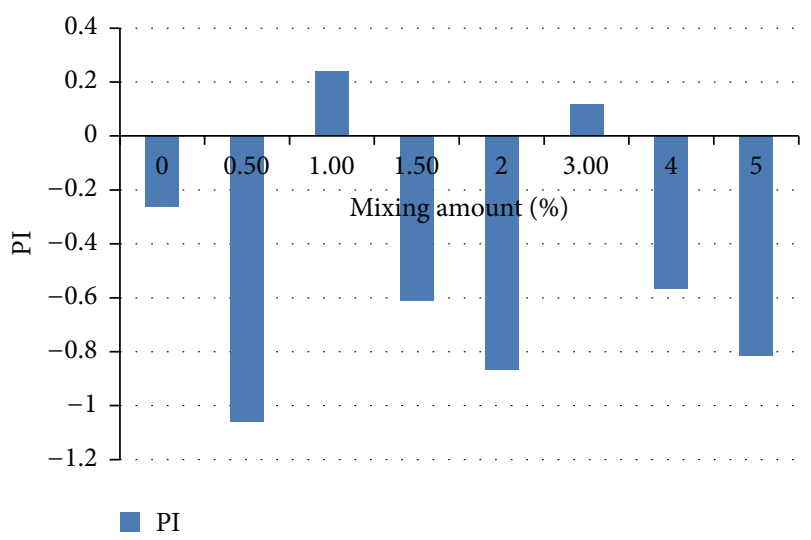

Figure 1: Penetration index value of modified asphalt in different mixing amount.

3.2. Softening Point and Equivalent Softening Point. The softening point and equivalent softening point of modified asphalt are calculated and the results are shown in Figure 2.

The requirement of the softening point in our specification for Grade A is more than or equal to $44^{\circ} \mathrm{C}$, and the test results all meet the primary requirements. Softening point test value increased with the mixing amount increase, but when more than $4 \%$ softening point began to decline. Equivalent softening points appear in two peaks in $1 \%$ and $3 \%$; it also began to decline when the dosage was more than $3 \%$.

3.3. Rotational Viscosity. The degree of asphalt fluidity is generally estimated by the viscosity. The purpose of rotational viscosity is to check the pumping and handling ability of asphalt storage, mixing, and compaction. It can be used for nonmodified and modified asphalt binders. In addition, six kinds of samples with different mixing amount were used in the test. The viscosity of $135^{\circ} \mathrm{C}$ is shown in Figure 3 .

Rotational viscosity of asphalt $135^{\circ} \mathrm{C}$ shown in Figure 3 had upward trend in $0 \%$ to $4 \%$, mainly due to the full reaction between of asphalt and silane silica, while the viscosity decreased when silane silica mixing amount is more than $4 \%$; this is because mixture contains excess modified material, and it cannot fully react; in other words silane silica maintains the original state in asphalt. Viscosity of asphalt should not be too large, and the standard in Superpave specification should be less than $3000 \mathrm{mPa} \cdot \mathrm{s}$, and it meets the specification

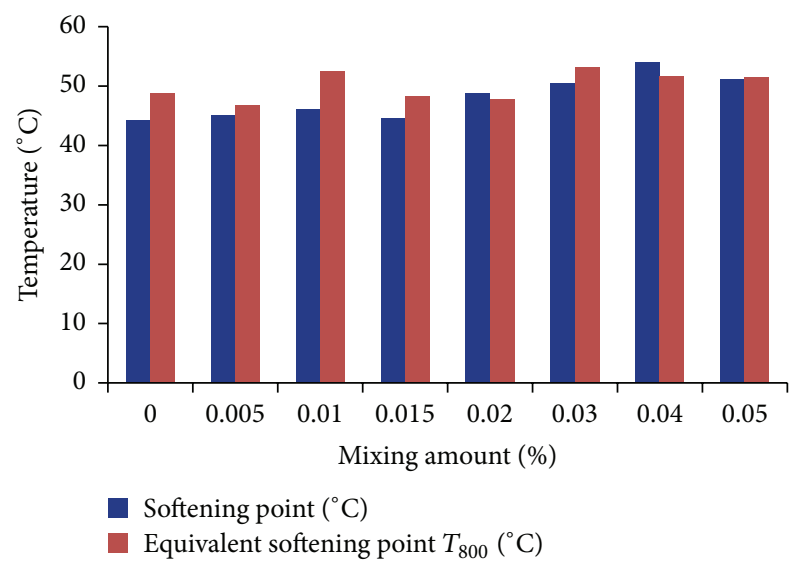

FIGURE 2: Softening point and equivalent softening point of modified asphalt in different mixing amount.

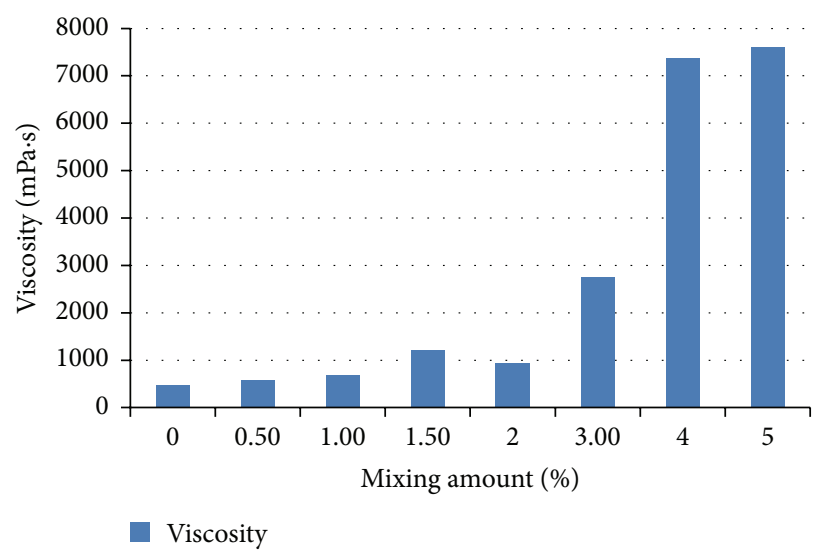

FIgURE 3: Rotational viscosity of modified asphalt in different mixing amount.

requirements when the silane silica content is less than $3 \%$. In addition, the mixing process of silane silica modified asphalt suggests that those chemical reactions and physical dispersion are likely to happen, and a new network structure might be formed. Furthermore, silane silica holds the potential to strengthen the control asphalt and to improve the recovery ability when stress is applied.

3.4. Equivalent Brittle Point. The calculation result of the equivalent brittle point is shown in Figure 4.

When the mixing amount is less than $3 \%$, equivalent brittle point is in wave state, and the $1 \%$ and $3 \%$ appear in peak value; when it is more than $3 \%$, equivalent brittle point showed rising trend. The main reason is that the excess part of modified material cannot react with asphalt and will play a negative effect. Equivalent brittle point in specification requirements for the A-level is $\leqslant-14.4^{\circ} \mathrm{C}$, and mixing amount will not be satisfied with the requirements if it is more than $4 \%$.

3.5. The Optimum Mixing Amount of Silane Silica. By the comparison and analysis of the test data, if silane silica content is more than or equal to $4 \%$, the penetration index, 


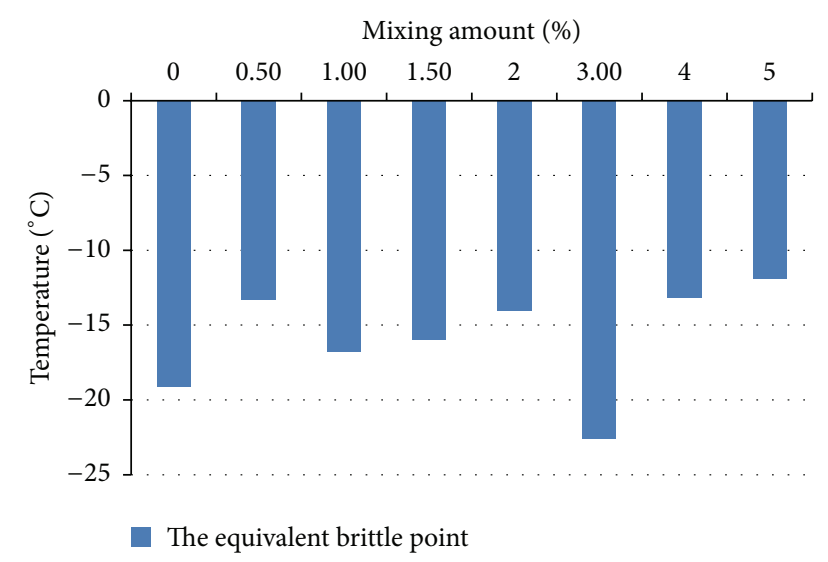

FIGURE 4: Equivalent brittle point of modified asphalt in different mixing amount.

viscosity, and equivalent brittle point of asphalt cannot meet the specification. Therefore, it is considered that content more than or equal to $4 \%$ cannot meet the requirements. A number of indices showed that performance of modified asphalt at $0 \%$ to $3 \%$ range had rising phase for the curve. PI value, equivalent softening point, and equivalent brittle point reached the peak when the mixing amount is $1 \%$ and $3 \%$; meanwhile viscosity at $3 \%$ is the best. In summary, the optimum mixing amount of silane silica modified asphalt is $3 \%$ so as to meet the requirements of the specifications and achieve the best effect.

\section{TG Analysis}

Thermal gravimetric analysis method was used to determine the weight of asphalt (burnout) with the curve of the temperature and determine the asphalt temperature stability. DTA and thermal gravimetric curves of asphalt samples were tested by TG209F3 thermal gravimetric analyzer, the gas environment of test instrument was nitrogen, the heating rate was $40^{\circ} \mathrm{C} / 10.0(\mathrm{~K} / \mathrm{min})$, and the temperature range was from 0 to $300^{\circ} \mathrm{C}$. The experiment mainly used nitrogen providing oxygen-free environment for the specimen to avoid reaction between oxygen and specimen. According to the TG analysis data, the relationship curve between temperature and DTA was drawn mainly to measure the physical and chemical changes in the asphalt under the sustained changing temperature environment. In addition, the curves declining represented the endothermic reaction happened, and the curves rising represented the exothermic reaction that happened.

The Tg and DTA analysis results are shown in Figures 5 and 6 .

The difference between first endothermic and exothermic peaks is not great between control asphalt and silane silica modified asphalt, but due to the fact that temperature test is only $300^{\circ} \mathrm{C}$, the temperature of next endothermic and exothermic peak cannot be determined. An exothermic peak was observed at $100^{\circ} \mathrm{C}$ from all the samples. Then the peak area of the control asphalt is much larger than the

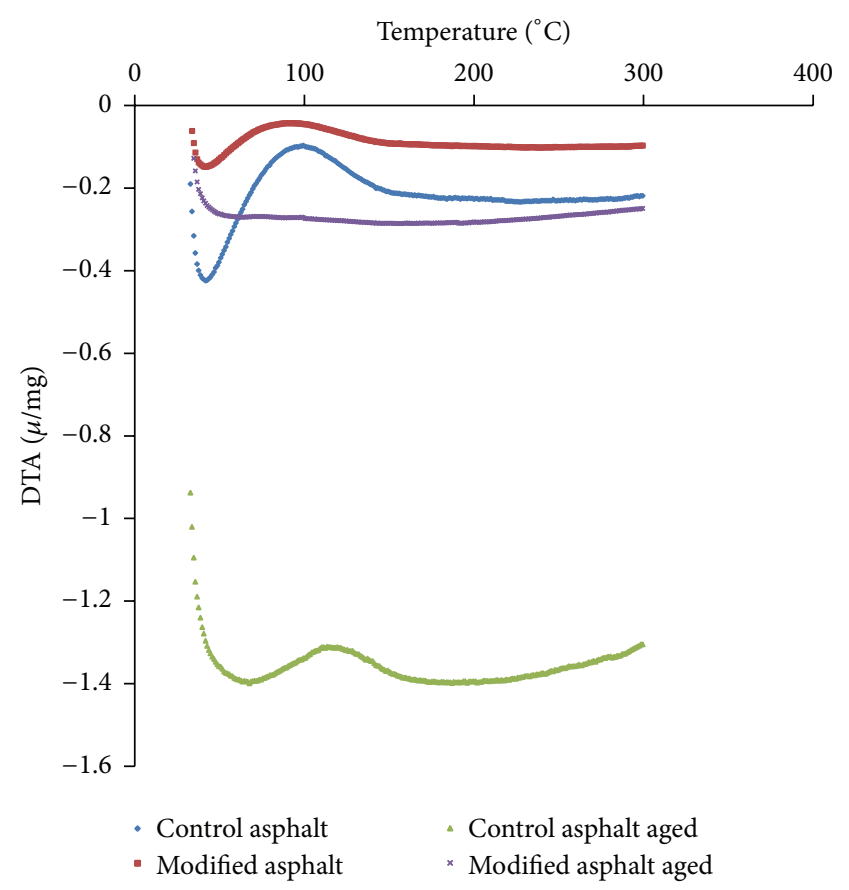

FIGURE 5: DTA analysis result of four kinds of samples.

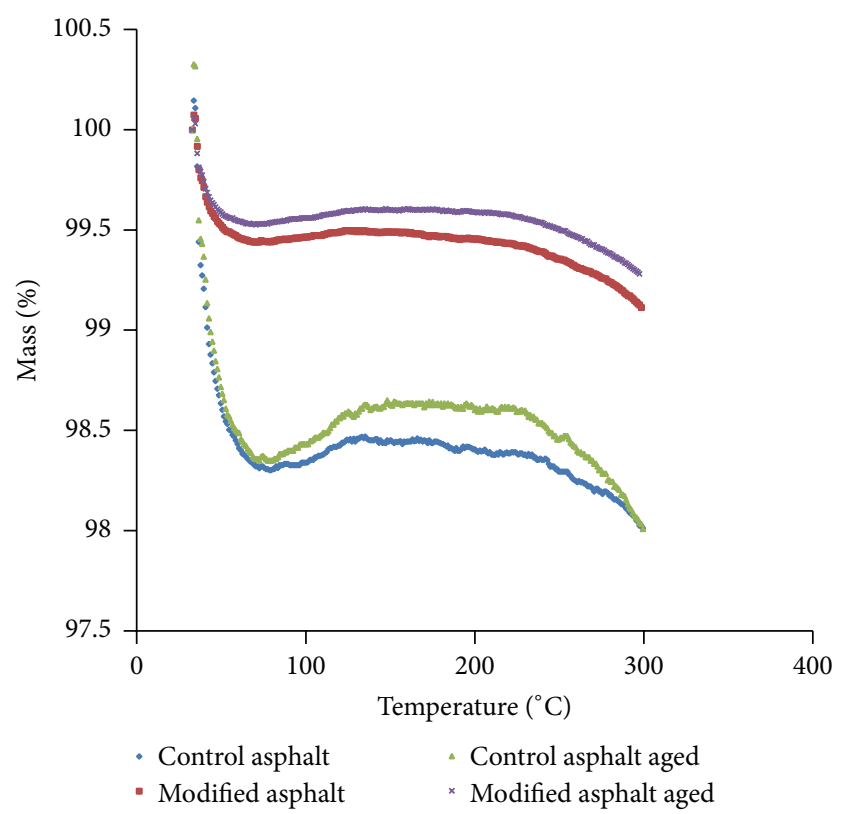

FIgURE 6: TG analysis result of four kinds of samples.

modified asphalt, and it can be judged that the heat effect of control asphalt is more significant and physical and chemical reactions during the temperature rising process are severer. So we can conclude that the temperature stability of modified asphalt is better.

The first endothermic peak of aging control asphalt was $75^{\circ} \mathrm{C}$, while that in aging modified asphalt was $125^{\circ} \mathrm{C}$, and the first exothermic peak in the former was $190^{\circ} \mathrm{C}$, while the latter has not reached the exothermic peak at $300^{\circ} \mathrm{C}$, so it can be 
known that the properties of aging modified asphalt are much better than aging control asphalt, because, after aging asphalt showed slower physical and chemical reaction activity, we can also evidently see that peak area of aging asphalt compared to the unaged asphalt is much smaller from Figure 5.

Asphalt structure is composed by four fractions of saturate, aromatic, resin, and asphaltine. Among them, light weight fractions in which the number of carbon atom is less than 4 will sublimate with the increasing of temperature, and the weight of asphalt will reduce. In comparison with the burning loss of control asphalt and modified asphalt, the amount of control asphalt was $1.6 \%$ at $105^{\circ} \mathrm{C}$, and the loss of modified asphalt was $0.5 \%$. There is little difference with endothermic peak and exothermic peak of two kinds of asphalt, while the peak area is much smaller than that of the control asphalt. In consideration of different peak areas, it can also be judged that the physical and chemical reactions of matrix asphalt are more active, so the amount of burning loss is even greater. Besides, the loss of the control asphalt at $300^{\circ} \mathrm{C}$ is $2.2 \%$, while the burning loss of the silane silica modified asphalt at $300^{\circ} \mathrm{C}$ is only $0.9 \%$; it can be seen that the high temperature stability of modified asphalt is better than that of the control asphalt. Meanwhile by comparison the burning loss at $300^{\circ} \mathrm{C}$ it is obviously seen that aging resistance of the modified asphalt is also better than the matrix asphalt.

By comparison with the burning loss of aging control asphalt and aging modified asphalt, the amount of aging control asphalt was $1.4 \%$ at $125^{\circ} \mathrm{C}$, while the amount of aging modified asphalt was $0.4 \%$. At $300^{\circ} \mathrm{C}$, the burning loss of aging control asphalt was $2.0 \%$, while the amount of the aging modified asphalt at 300 was only $0.72 \%$. So we can conclude that the high temperature stability and aging resistance of modified asphalt were significantly improved after aging.

In summary, in both unaged modified asphalt and aging modified asphalt, the chemical compositions and chemical properties by differential thermal analysis are better than the control asphalt. TG test showed that the performance of asphalt such as viscosity, tensile strength, high temperature stability, and antiaging performance had been improved significantly by mixing with silane silica. That is due to not only the coupling effect that silane has on asphalt, but also the activation and modification effect silica on asphalt which can promote the chemical reaction between asphalt and silane, and silane also will improve the compatibility between silica and asphalt, strengthen the interaction of the interface between them, and improve the tear strength of asphalt.

\section{The Road Performance Test}

A series of road performances were conducted to determine the superiority of asphalt mixture modified by silane silica, and it can provide theoretical support for the application of the modified asphalt and mixture.

The effect of modified asphalt on the high temperature stability of the mixture was verified by the rutting test. The effect of modified asphalt on the water stability of mixture was verified by water boiling test, Marshall immersion test, freezethaw split test, and Marshall test, and the effect of modified
TABLE 3: Results of rutting test.

\begin{tabular}{lc}
\hline Mixture type & Dynamic stability number $($ time $/ \mathrm{mm})$ \\
\hline Control asphalt mixture & 2700.16 \\
Modified asphalt mixture & 3391.96 \\
\hline
\end{tabular}

TABLE 4: Results of immersion Marshall test.

\begin{tabular}{lcc}
\hline Mixture type & $\begin{array}{c}\text { Control asphalt } \\
\text { mixture }\end{array}$ & $\begin{array}{c}\text { Modified } \\
\text { asphalt mixture }\end{array}$ \\
\hline Stability (kN) & 11.27 & 14.03 \\
Flow value (mm) & 2.51 & 2.79 \\
Water immersion 48h & 7.36 & 10.39 \\
stability (kN) & 1.18 & 1.59 \\
Water immersion 48h & 65.3 & 74.05 \\
flow value (mm) & & \\
Residual stability (\%) & & \\
\hline
\end{tabular}

TABLE 5: Result of vacuum water saturated Marshall test.

\begin{tabular}{lcc}
\hline Mixture type & $\begin{array}{c}\text { Control asphalt } \\
\text { mixture }\end{array}$ & $\begin{array}{c}\text { Modified } \\
\text { asphalt mixture }\end{array}$ \\
\hline Stability (kN) & 11.27 & 14.03 \\
Flow value (mm) & 2.51 & 2.79 \\
Vacuum saturation 48 h & 6.82 & 8.99 \\
stability (kN) & & \\
Vacuum saturated 48 h & 1.82 & 1.52 \\
flow value (mm) & 60.51 & 64.08 \\
Residual stability (\%) & & \\
\hline
\end{tabular}

asphalt on antiaging property of modified asphalt was verified by using the short-term aging test.

5.1. Research on High Temperature Stability. The rutting test results of asphalt mixture with $3 \%$ mixing amount and control asphalt mixture are shown in Table 3.

From Table 3, we can see that the modified asphalt mixture can improve the dynamic stability by $25.6 \%$. The effect of the addition of silica silane on the high temperature stability of the mixture is obvious.

5.2. Research on Water Stability. The immersion Marshall test results are shown in Table 4.

The stability of the modified asphalt mixture is higher than the control asphalt mixture. The additional silane silica in the asphalt mixture improves the stability about $24.4 \%$, while after water immersion the value is up to $41.2 \%$. The residual stability of the modified asphalt mixture is also higher than the control asphalt mixture.

Vacuum saturated Marshall test results are in Table 5.

After modification of the stability of the mixture after vacuum saturation was improved by about $31.8 \%$, the residual stability of modified asphalt mixture also increased from $60.51 \%$ to $64.08 \%$.

The freeze-thaw split test results were shown in Table 6.

After modification of the splitting strength of the mixture was improved by about $22 \%$, after freezing and thawing cycles 
TABLE 6: Result of freeze-thaw split test.

\begin{tabular}{lcc}
\hline Mixture type & $\begin{array}{c}\text { Control asphalt } \\
\text { mixture }\end{array}$ & $\begin{array}{c}\text { Modified } \\
\text { asphalt mixture }\end{array}$ \\
\hline $\begin{array}{l}\text { Nonfreezing and thawing } \\
\text { splitting strength (KN) }\end{array}$ & 11.6 & 14.16 \\
$\begin{array}{l}\text { Freezing and thawing } \\
\text { splitting strength (KN) }\end{array}$ & 9.45 & 11.91 \\
$\begin{array}{l}\text { Freeze-thaw splitting } \\
\text { tensile strength ratio (\%) }\end{array}$ & 81.47 & 84.11 \\
\hline
\end{tabular}

TABLE 7: Result of boiling test.

\begin{tabular}{lcc}
\hline Test type & Boiling, 3 min & Boiling, 20 min \\
\hline Control asphalt & Grade 2 & Grade 1 \\
Modifier asphalt & Grade 5 & Grade 5 \\
\hline
\end{tabular}

the value was up to $26 \%$. The splitting tensile strength ratio of modified asphalt was $84.11 \%$; in contrast this value of control asphalt mixture was 81.47 .

The boiling test was used to verify the modification effect of adhesion between asphalt and stone, and the test results are as shown in Table 7.

From Table 7 it can be seen that the adhesion of asphalt and stone is very poor without adding silane silica. By the boiling test, the membrane of control asphalt dropped significantly after $1 \mathrm{~min}$ boiling, and the aggregate has been exposed more than half after $3 \mathrm{~min}$, while the effect of silane silica added in asphalt is obvious, and after boiling for $20 \mathrm{~min}$ adhesion reached grade 5 . Through the experiment, we can see that the silane silica added in asphalt greatly improved the adhesion and enhanced the consolidation strength of the oilstone interface.

The above four test results showed that silane silica modified asphalt mixture had excellent effect to improve the water stability of asphalt mixture.

5.3. Research on Antiaging Performance. In accordance with the asphalt mixture test procedures T0734 short-term aging method, asphalt mixture was heated in the $135^{\circ} \mathrm{C} \pm 1^{\circ} \mathrm{C}$ oven for $4 \mathrm{~h} \pm 5 \mathrm{~min}$, mixture must be stirred once an hour during the aging process.

Then the specimens were formed to measure the index of the residual stability of the water immersion, the residual stability of the vacuum saturation, and tensile strength ratio of freeze-thaw splitting strength before and after aging. The test results are as shown in Table 8 .

From the test results in Table 8, the water stability of the two samples was decreased after aging, while the decreasing amplitude of modified asphalt mixture was less than that of control asphalt mixture, and the indexes of modified asphalt after aging are better than asphalt unaged which indicates that modified asphalt mixture significantly improved antiaging properties.

\section{Conclusions}

Silane in silane silica with adsorption and invasion function can reduce the surface tension and enhance the hydrophobicity
TABLE 8: Result of aging test.

\begin{tabular}{lcc}
\hline Mixture type & $\begin{array}{c}\text { Control } \\
\text { asphalt } \\
\text { mixture }\end{array}$ & $\begin{array}{c}\text { Modified } \\
\text { asphalt mixture }\end{array}$ \\
\hline $\begin{array}{l}\text { The residual stability of the } \\
\text { water immersion before and } \\
\text { after aging (\%) }\end{array}$ & $65.3 / 62.6$ & $74.05 / 72.7$ \\
$\begin{array}{l}\text { The residual stability of the } \\
\text { vacuum saturation before and } \\
\text { after aging (\%) }\end{array}$ & $60.51 / 55.7$ & $64.08 / 62.3$ \\
$\begin{array}{l}\text { Tensile strength ratio of } \\
\text { freeze-thaw splitting strength } \\
\text { before and after aging (\%) }\end{array}$ & $81.47 / 77.3$ & $84.11 / 83.3$ \\
\hline
\end{tabular}

of the asphalt and also form key joints and improve the adhesion between asphalt and aggregate. Silica with activation and modification function can improve the tear strength of the asphalt. The objective of this study is to evaluate the modified effect and process with silane silica in order to improve the overall road performance of asphalt mixture and enhance the adhesion between asphalt and aggregate. The specific conclusions are as follows:

(1) Silane silica was innovatively used as a new type of modified filler.

(2) The production process of modified asphalt is as follows: First control asphalt was heated to molten state; then silane silica was added into control asphalt at certain concentrations by weight of the control asphalt and mixed in the high-speed shear machine. During the mixing, the asphalt samples were kept at constant temperature of $160^{\circ} \mathrm{C}$ and blended using a shear rate of $4000 \mathrm{r} / \mathrm{min}$ for an hour.

(3) Based on the limited laboratory work done in this study, it can be concluded that the addition of $3 \%$ silane silica is the optimum mixing amount to improve the performance characteristics of modified asphalt in various conditions.

(4) TG test showed that tear strength, high temperature resistance, and aging resistance of the modified asphalt are obviously improved. The superiority of modified asphalt was proved from the point of chemical analysis.

(5) The water stability of modified asphalt mixture has been significantly improved; meanwhile the antiaging performance and high temperature stability of the modified asphalt mixture are also improved obviously.

\section{Conflict of Interests}

The authors declare that there is no conflict of interests regarding the publication of this paper. 


\section{Acknowledgment}

The research work described herein was funded by the National Nature Science Foundation of China (NSFC) (Grant no. 51178204). This financial support is gratefully acknowledged.

\section{References}

[1] B. Sengoz and G. Isikyakar, "Evaluation of the properties and microstructure of SBS and EVA polymer modified bitumen," Construction and Building Materials, vol. 22, no. 9, pp. 18971905, 2008.

[2] M. S. Cortizo, D. O. Larsen, H. Bianchetto, and J. L. Alessandrini, "Effect of the thermal degradation of SBS copolymers during the ageing of modified asphalts," Polymer Degradation and Stability, vol. 86, no. 2, pp. 275-282, 2004.

[3] K.-D. Jeong, S.-J. Lee, S. N. Amirkhanian, and K. W. Kim, "Interaction effects of crumb rubber modified asphalt binders," Construction and Building Materials, vol. 24, no. 5, pp. 824-831, 2010.

[4] L. Xin, Research of Modified Asphalt Binder based on Asphalt Aggregate Interface Enhancement, Jilin University, Changchun, China, 2012.

[5] M. J. Khattak, A. Khattab, H. R. Rizvi, and P. Zhang, "The impact of carbon nano-fiber modification on asphalt binder rheology," Construction and Building Materials, vol. 30, no. 5, pp. 257-264, 2012.

[6] W. Ning, Research on the Performance of the Basalt Fiber and Modified Asphalt, China University of Geosciences, 2013.

[7] T. Jiyu, Composition and Performance Test of Fiber Asphalt Mixture, Zhengzhou University, Zhengzhou, China, 2013.

[8] Z. You, J. Mills-Beale, J. M. Foley et al., "Nanoclay-modified asphalt materials: preparation and characterization," Construction and Building Materials, vol. 25, no. 2, pp. 1072-1078, 2011.

[9] S. G. Jahromi and A. Khodaii, "Effects of nanoclay on rheological properties of bitumen binder," Construction and Building Materials, vol. 23, no. 8, pp. 2894-2904, 2009.

[10] Z. Zhang and G. Hu, "Research on properties of low temperature cracking Silica modified asphalt mixture," Journal of Beijing University of Technology, vol. 32, no. 11, pp. 1007-1010, 2006.

[11] S. Chen and Y. Yu, "Effect of silica on properties of SBS modified asphalt," Petroleum Asphalt, vol. 21, no. 1, pp. 18-22, 2007.

[12] M. Lin, Research the Properties of PCF-Diatomite Composite Modified Asphalt, Jilin University, Changchun, China, 2014.

[13] H. Yao, Z. You, L. Li et al., "Rheological properties and chemical bonding of asphalt modified with nanosilica," Journal of Materials in Civil Engineering, vol. 25, no. 11, pp. 1619-1630, 2012.

[14] N. I. M. Yusoff, A. A. S. Breem, H. N. M. Alattug, A. Hamim, and J. Ahmad, "The effects of moisture susceptibility and ageing conditions on nano-silica/polymer-modified asphalt mixtures," Construction and Building Materials, vol. 72, pp. 139-147, 2014.

[15] K. Chrissafis, K. M. Paraskevopoulos, G. Z. Papageorgiou, and D. N. Bikiaris, "Thermal and dynamic mechanical behavior of bionanocomposites: fumed silica nanoparticles dispersed in poly(vinyl pyrrolidone), chitosan, and poly(vinyl alcohol)," Journal of Applied Polymer Science, vol. 110, no. 3, pp. 1739-1749, 2008.

[16] H. Kun, C. Lan, and L. Xuan, "Modified silica and silicone powder on properties of styrene butadiene rubber," Rubber Industry, vol. 62, no. 1, pp. 21-26, 2015.
[17] Y. Zhu, "Preparation of rubber with silane silica nano filler for rubber," Rubber Reference Method, vol. 37, no. 6, pp. 7-11, 2007.

[18] Q. Liu, H. Zhao, and H. Hu, "Surface modification of silica reinforced SSBR," Performance Synthetic Rubber Industry, vol. 37, no. 2, pp. 144-148, 2014.

[19] L. L. Song, X. Jie, and G. Yu, "Rubber filler mutual effect of styrene butadiene rubber (SBR)/silica composite performance," Science China Chemistry, vol. 11, pp. 1-5, 2014.

[20] E. Hesami, D. Jelagin, N. Kringos, and B. Birgisson, "An empirical framework for determining asphalt mastic viscosity as a function of mineral filler concentration," Construction and Building Materials, vol. 35, pp. 23-29, 2012. 

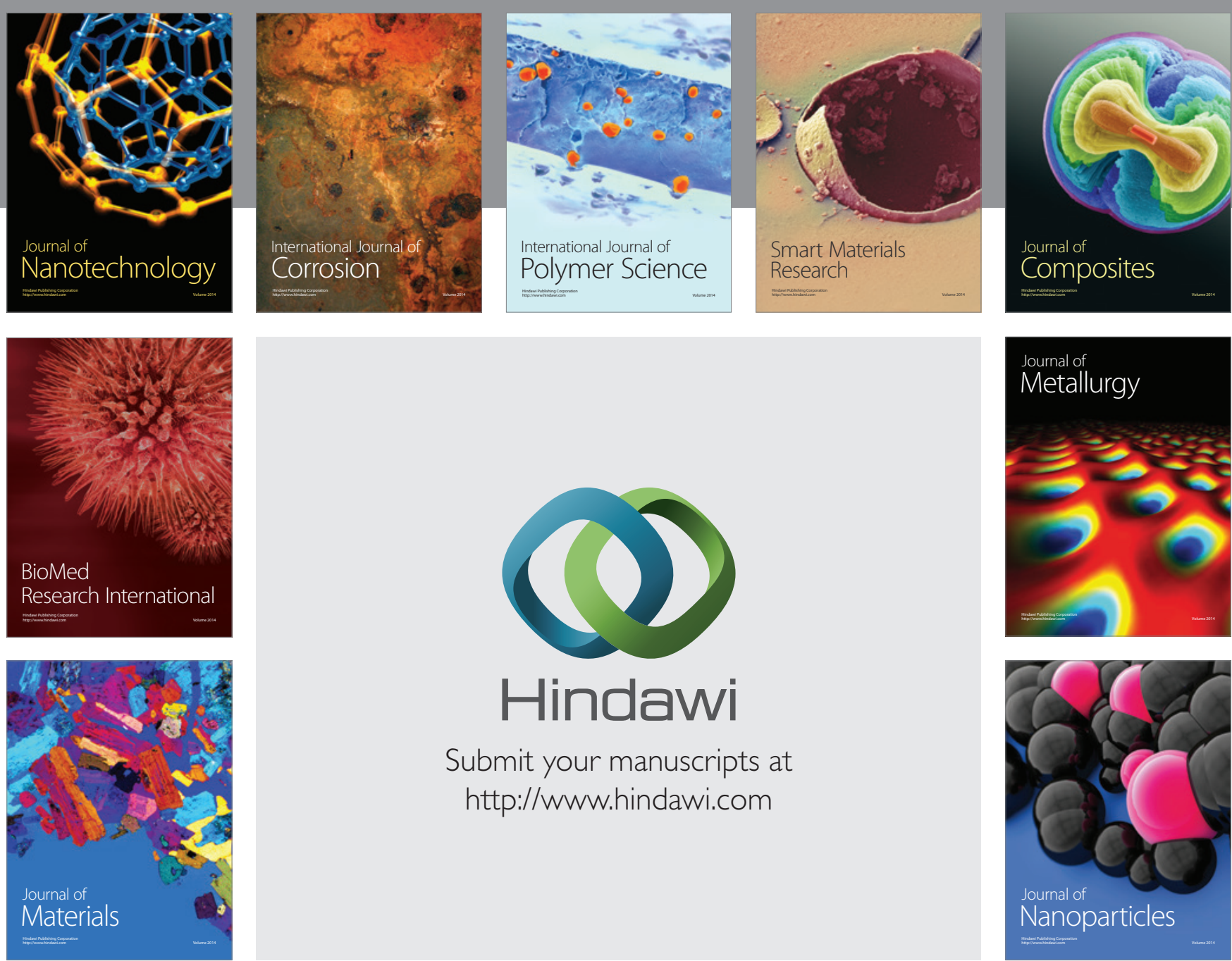

\section{Hindawi}

Submit your manuscripts at

http://www.hindawi.com

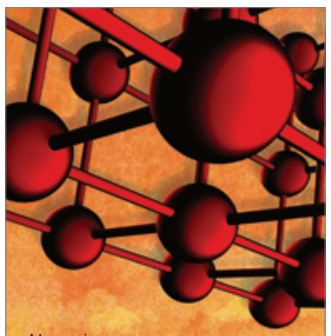

Materials Science and Engineering
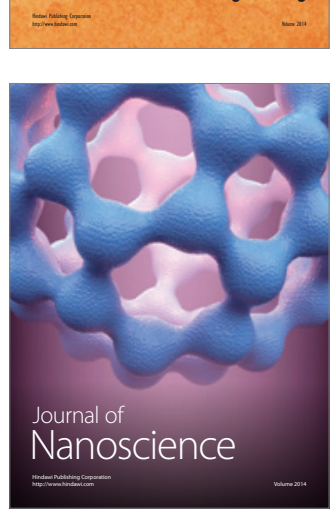
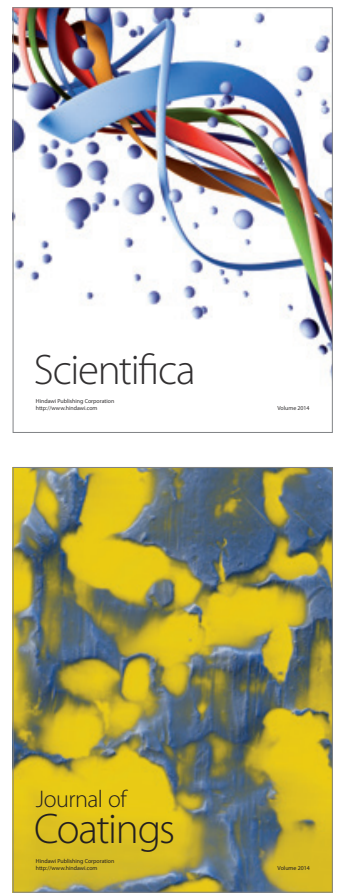
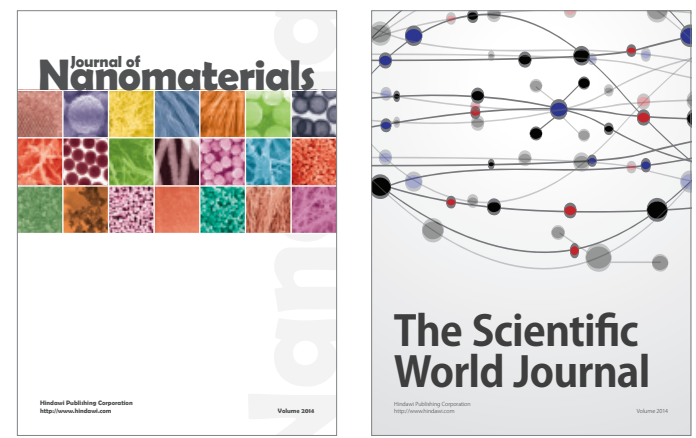

The Scientific World Journal
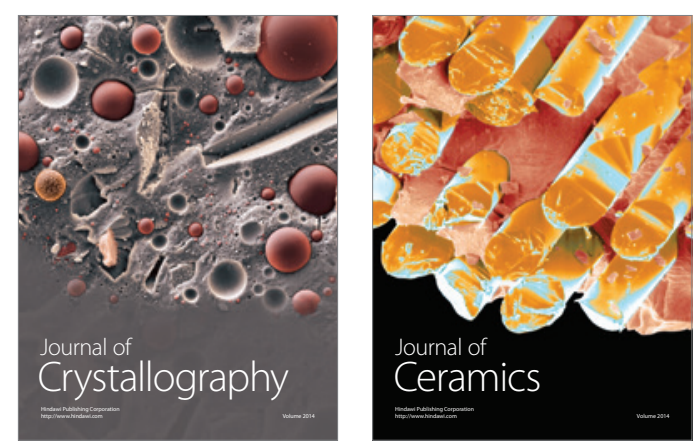
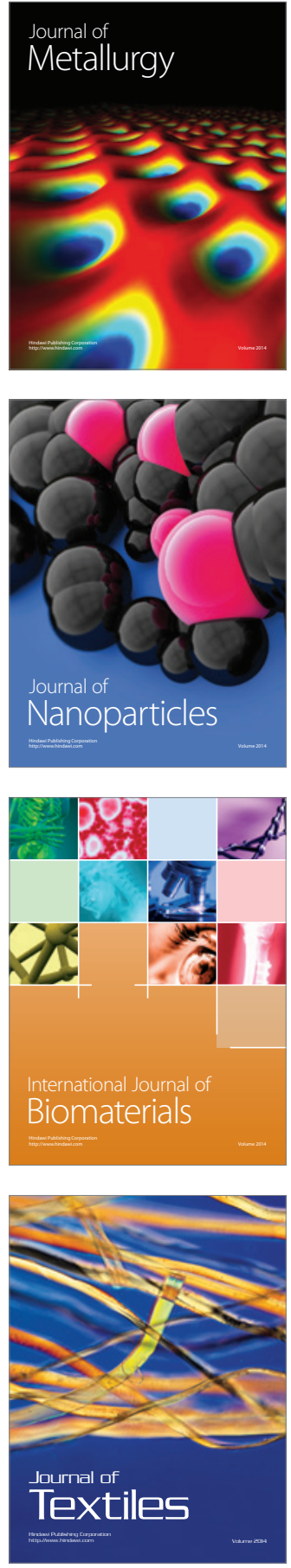